Recebido: 11/01/2015

Aprovado: 21/03/2015

\title{
Inimigos da Luz: A antifilosofia no jornal brasileiro A Voz da Religião
}

José Lourenço de Sant'Anna Filho*

Resumo: Os estudos sobre a antifilosofia ganharam espaço na historiografia atual. Destacam-se, nesse processo de renovação, os historiadores Didier Masseau e Darrin McMahon que têm publicado trabalhos com o propósito de compreender esse movimento de ataque ao lluminismo. Os "anti-iluministas", contemporâneos dos philosophes Voltaire, Rousseau e Diderot, tinham por objetivo criticar o pensamento e a ascensão política e social dos representantes das "Luzes". As manifestações antifilosóficas circularam na imprensa religiosa brasileira. Distingue-se nesse movimento de propagação de ideias o jornal católico A Voz da Religião de 1846, escrito pelo cônego Francisco José Tavares da Gama. O presente trabalho objetiva analisar tal periódico, de modo a perceber a circulação e apropriação dessas ideias antifilosóficas no Império do Brasil.

Palavras-chave: Antifilosofia; Espinosa; Voltaire.

Abstract: The studies about anti-philosophy have gained space in modern historiography. The historians Didier Masseau and Darrin McMahon dedicated works with the purpose of understanding this movement of attack the Enlightenment. The anti-philosophes, contemporaries of Voltaire, Rousseau and Diderot had a purpose of criticizing the mindset and the social and political rising of representatives of the Enlightenment. In Brazil, anti-philosophy ideas circulated in the religious press. The Catholic newspaper A Voz da Religião, 1846, written by Francisco José Tavares da Gama was the main one. This paper aims to analyze this journal in order to examine the circulation and appropriation of the anti-philosphy ideas in the Empire of Brazil.

Keywords: Anti-philosophy; Spinoza; Voltaire.

* Bacharel e licenciado em História pela Universidade de Brasília. E-mail para contato: lourenco.santanna@gmail.com 


\section{Introdução}

A antifilosofia ${ }^{1}$ foi um movimento de crítica ao Iluminismo que surgiu na França ao longo do século XVIII. ${ }^{2}$ Paralelamente às publicações dos textos dos filósofos surgiram opiniões contrárias a algumas ideias defendidas pela filosofia ilustrada, principalmente, a importância atribuída à razão humana para a compreensão da natureza e da sociedade. Segundo os antifilósofos, os iluministas publicavam textos contra a Igreja Católica, a fé e as Sagradas Escrituras.

Essas críticas tiveram ampla divulgação no meio intelectual europeu do século XVIII. Contudo, essa literatura não foi tão pesquisada como os textos dos filósofos. Em 1939, Robert Palmer dissertou acerca da relação entre as ideias iluministas e católicas. (PALMER, 1939). Isaiah Berlin publicou, em 1970, um artigo utilizando a expressão Counter-Enlightenment. Berlin examinou a antifilosofia em sua manifestação posterior à Revolução Francesa. (BERLIN, 2001). Recentemente, alguns historiadores como Darrin McMahon, Didier Masseau, Jonathan Israel, Graeme Garrander e Zeev Sthernell têm se dedicado a pesquisar a antifilosofia em suas manifestações anteriores e posteriores à revolução.

No período anterior à revolução, surgiram jornais e livros com o intuito de atacar a filosofia das Luzes. Calcula-se que mais de duzentos mil livros foram impressos com esse objetivo. (McMAHON, 2001:24). Havia, inclusive, prêmios patrocinados pela Societé des Amis de la Religion et des Lettres destinados aos melhores trabalhos que defendessem a religião. (McMAHON, 2001). Os jornais Année Littéraire, Journal Historique et Littéraire e o Journal Ecclésiastique, eram os principais responsáveis pela disseminação das ideias antifilosóficas na França. (McMAHON, 2001) . O jornalista Élie Catherine Fréron, por exemplo, tece comentários severos ao pensamento de Voltaire, acusando-o de covarde, malfeitor e miserável. (McMAHON, 2001). Alguns professores da Sorbonne temiam que os textos dos philosophes minassem a fé religiosa e a autoridade constituída. (McMAHON, 2001). O status social que os philosophes alcançaram na França, ao receberem cargos públicos, frequentarem os grandes salões, as academias literárias e científicas, provocou a reação de pessoas ligadas a alguns círculos intelectuais da sociedade, sobretudo porque,

\footnotetext{
${ }^{1}$ Anti-philosophe era a expressão usada pelos contemporâneos. Optou-se pela tradução dessa expressão, evitando o emprego de anti-iluminismo.

${ }^{2}$ Emprega-se o termo Iluminismo, no singular, para se referir ao movimento de ideias que ocorreu na Europa setecentista, embora a historiografia mais recente sobre o tema questione a expressão e defenda o uso do termo Iluminismos, no plural.
} 
segundo os antifilósofos, os maiores inimigos da religião não deveriam ser laureados dessa maneira.

A literatura antifilosófica era composta, em sua maioria, por textos produzidos por homens ligados à Igreja. Embora houvesse, no âmbito da antifilosofia, alguns homens dedicados ao comércio e alguns nobres, predominaram os religiosos. Os abades Gaultier, Chaudon e Yvon, por exemplo, publicaram textos que criticavam explicitamente as ideias defendidas pelos filósofos. O abade Gaultier criticou severamente os textos de Montesquieu, alegando que seus escritos eram um perigo para o Estado e para a Igreja e deveriam ser censurados. (GUYAUX apud GAULTIER, 2003). O abade Chaudon, por sua vez, criticou o Dicionário Filosófico de Voltaire e publicou, em resposta, o Dictionnaire anti-philosophique em 1767. (MASSEAU, 2000: 25). Já o abade Yvon, embora colaborador da Enciclopédie, em 1751, com os verbetes athée e âme, não hesitou em criticar Rousseau. (MASSEAU, 2000).

A eclosão da Revolução Francesa assinalou uma aproximação do pensamento dos antifilósofos com as ideias contra-revolucionárias.(McMAHON, 2001:56). De acordo com a interpretação de alguns antifilósofos do período pós-revolucionário, a Revolução Francesa expressava uma punição de Deus contra todos aqueles que haviam blasfemado contra o seu santo nome. Deus estava vingando-se de toda incredulidade do "Século Filosófico". (McMAHON, 2001:57). O francês Joseph de Maistre foi um dos primeiros a interpretar as causas da Revolução por esse viés: como punição divina. Outro antifilósofo pósrevolucionário, o abade Augustin Barruel, entendeu que a Revolução Francesa havia sido resultado de um "complô" preparado pelos filósofos. (McMAHON, 2001:59). Barruel não foi o único a interpretar a Revolução dessa perspectiva; o religioso Jean-Baptiste Gaultier também apoiava essa ideia. (MASSEAU, 2000: 21). Essa interpretação teve uma repercussão tão ampla no período pós-revolucionário que houve, inclusive, censores do Vaticano que se apropriaram dela, e concluíram que o objetivo dos philosophes era destruir o Antigo Regime. (McMAHON, 2001:63).

As críticas ao pensamento ilustrado não ficaram restritas à França, e, tampouco, ao século XVIII. Houve manifestações desse pensamento em diversas partes da Europa, e encontram-se ecos também na América. Avançaram no século XIX, tendo sempre como referência a Revolução Francesa.

No Brasil, o jornal católico A Voz da Religião, editado pelo padre Francisco José Tavares da Gama, pode ser considerado um exemplo do que se convencionou chamar, desde o século XVIII, antifilosofia. Criado em Recife em 1846, era distribuído aos domingos e 
continha sonetos, salmos, reflexões sobre a importância da religião, artigos e crônicas de autoria do padre e de outros religiosos. No jornal encontram-se, também, traduções de textos publicados originalmente no jornal francês L'Ami de la Religion.

Os artigos de A Voz da Religião constituem o objeto desse trabalho. Em um primeiro momento, a atenção estará voltada para as críticas que o padre Tavares da Gama dirigiu a alguns representantes da filosofia ilustrada. Embora ele tenha criticado vários ilustrados, como por exemplo, David Hume, Kant, Montesquieu, Diderot e d'Alembert, este trabalho limitar-se-á às críticas dirigidas a dois autores: Espinosa e Voltaire. ${ }^{3}$ Espinosa foi interpretado pelo padre como o pai de uma literatura "athea" e Voltaire, por sua vez, como o precursor de uma literatura repleta de "hum deísmo sem pudor." (GAMA, 1846:7). Tanto Espinosa como Voltaire são autores polêmicos e alvos de distintas interpretações. Este artigo centra-se na interpretação desses dois autores pelo eclesiástico.

Como observou Jonathan Israel, Espinosa tornou-se um filósofo maldito, embora tenha sido mais criticado do que compreendido. Suas ideias ficaram conhecidas nos séculos XVII e XVIII como "espinozismo", expressão que sinalizava alerta para todos os cristãos. (ISRAEL, 2001:22). Suas ideias tornaram-se um desafio para a fé e para a autoridade da Igreja e poderiam, segundo os cristãos em geral, ter consequências nefastas na esfera da política. Quanto a Voltaire, o seu deísmo foi alvo de ataques dos católicos.

Como fontes primárias serão utilizados, além dos artigos de $A$ Voz da Religião e alguns exemplares da Revista do Instituto Histórico de Goianna, alguns textos dos filósofos selecionados.

\section{A Voz da Religião: a antifilosofia no Brasil}

No Brasil, a apropriação de algumas ideias ilustradas deu-se, em grande parte, por intermédio de uma elite intelectual da colônia que tinha contato com a literatura europeia. Muitos funcionários régios, ao serem transferidos para a colônia, traziam consigo ideias ilustradas a respeito da razão e da natureza. Essas ideias e, ao mesmo tempo o debate em torno delas, estenderam-se ao século XIX.

No Rio de Janeiro, o jornal $O$ Patriota divulgou algumas das novas ideias e contribuiu para a sua circulação no império por meio da imprensa. (KURY, 2008). A divulgação dessas ideias incomodou parte dos intelectuais da colônia, sobretudo, os eclesiásticos. Os homens

\footnotetext{
${ }^{3}$ A obra de Espinosa, embora do século XVII, teve ampla repercussão em alguns filósofos do século XVIII. 
ligados à religião católica temiam que a leitura dos textos de Voltaire, de Montesquieu e dos enciclopedistas ocupassem o lugar das Sagradas Escrituras e que a influência do pensamento desses filósofos tornasse-os mais atraentes do que as instruções eclesiásticas. Alguns periódicos como $O$ Catholico e $O$ Amigo dos Homens surgiram nesse contexto, com o intuito de reafirmar alguns valores cristãos na sociedade. ${ }^{4}$

O jornal A Voz da Religião é um bom exemplo do empenho, por parte de religiosos, em divulgar os danos que a razão poderia causar quando desvinculada da fé e da Revelação. "A Voz da Religião deve ecoar pelos quatro ventos", pois considerava-se um dever dos homens da religião alertar para os perigos que os livros cheios de "hum deismo sem pudor" podiam causar. (GAMA, 1846:7).

A Voz da Religião surgiu porque o cônego Tavares da Gama sentia que a sociedade estava sendo ameaçada por uma "seita philosophica". (GAMA, 1846:7). A proliferação dos livros ilustrados, vendidos a baixos preços, facilitava a divulgação dos debates filosóficos europeus que colocavam à prova alguns conceitos caros ao catolicismo. Os perigos da influência da filosofia das Luzes deveriam ser combatidos: "bem persuadidos de que no actual estado da sociedade, em que com tanto empenho se propagão as luzes, em todos os ramos, não deve ser indiferente a propagação das ideias religiosas [...].”( GAMA, 1846:1). Esse posicionamento situa o periódico no conjunto de textos considerados antifilosóficos.

O redator Tavares da Gama era um homem ilustrado; conhecia a literatura iluminista e dominava as Sagradas Escrituras, o direito canônico e eclesiástico. (ALMEIDA, 1871:115). O padre lia os textos dos filósofos iluministas com desvelo, preocupado em compreender o raciocínio dos autores. Ao longo de seus escritos, Tavares da Gama destacava o que considerava equívocos cometidos por alguns filósofos. Esses equívocos, em sua opinião, eram cometidos porque os filósofos construíam seus argumentos com base apenas na razão. (GAMA, 1846:1). Essa pretensão ignorava a importância de alguns aspectos fundamentais para o raciocínio e o conhecimento: a Revelação Divina. De acordo com o padre, pretender que a razão fosse mais importante do que a revelação divina era um dos maiores erros dos filósofos.

Os conhecimentos sobre filosofia foram adquiridos pelo padre Tavares da Gama ainda na juventude, em Pernambuco. Seu professor, José Bernadino Sena ministrou-lhe aulas de

\footnotetext{
${ }^{4}$ Não se pode afirmar se esses dois periódicos contribuíram para disseminação das ideias antifilosóficas no Império do Brasil. Entretanto, o padre Tavares da Gama creditou a esses dois jornais a motivação para criar seu próprio jornal.
} 
filosofia, história e latim, dando prosseguimento aos seus estudos iniciados em Portugal, no Colégio dos Nobres. (ALMEIDA, 1871:90).

Sua vasta erudição em diferentes áreas do conhecimento rendeu-lhe uma vaga na cadeira de filosofia em sua Congregação, em Recife. Suas aulas foram tão influentes que mesmo após deixar o cargo - por motivos desconhecidos - permaneceu ministrando cursos de filosofia em sua própria casa, tendo diversos discípulos das mais altas "reputações litterarias ou políticas do país". (ALMEIDA, 1871:90). Um de seus mais proeminentes alunos, o político e escritor pernambucano José da Natividade Saldanha Marinho, dedicou em seu livro um poema ao seu ilustre professor. (SALDANHA, 1822:97-99).

Embora tenha sido um homem versado nas "belas artes", Tavares da Gama não deixou grande produção bibliográfica, apenas os artigos que compõem o jornal $A$ Voz da Religião. (ALMEIDA, 1871:115). Suas reflexões giram em torno da preocupação com a influência, cada vez mais significativa, da filosofia, considerada por ele, irreligiosa. Com essa preocupação em mente é que o padre analisa textos de Espinosa e Voltaire, destacando, sobretudo, os aspectos negativos da filosofia, tanto no que se refere à moral, como ao sistema político e religioso. Ênfase é dada à crítica ao deísmo e ao ateísmo.

\section{A filosofia irreligiosa: do deísmo ao ateísmo}

Com o objetivo de compreender o pensamento de Voltaire e Espinosa, o padre recorreu a diversos textos de outros autores para auxiliá-lo nas suas reflexões sobre o pensamento desses dois filósofos. ${ }^{5}$ A ligação que existe entre Espinosa - autor do século XVII - e Voltaire - autor do século XVIII - repousa em dois aspectos. Em primeiro lugar, Tavares da Gama considerava ambos responsáveis pela proliferação da literatura irreligiosa que, em sua opinião deveria ser combatida. Em segundo lugar, esses dois autores eram representativos do ateísmo e do deísmo, respectivamente. Voltaire representava o deísmo, e Espinosa o ateísmo. Esses dois filósofos teriam propagado ideias contrárias à Igreja, e, portanto, o eclesiástico considerava-as anti-cristãs. (GAMA, 1848:154).

Ao criticar Voltaire, o símbolo máximo do iluminismo francês, e Espinosa, o autor que criticou diversos aspectos da bíblia ainda no século XVII, Tavares da Gama posiciona-se de forma bem clara contra filosofias que pretendiam orientar-se apenas pela razão.

\footnotetext{
${ }^{5}$ Textos dos jornais l'Ami de la Religion e do Jornal da Sociedade Catholica auxiliaram nas reflexões do padre Tavares da Gama.
} 
Segundo Tavares da Gama, ao conduzir-se apenas pela razão, essas duas "seitas philosophicas" esqueciam-se da orientação dada pelo Evangelho, pelos eclesiásticos e pela Revelação. Embora defendessem a crença em um Deus, os deístas negavam a Revelação. Segundo o padre, ao renegar alguns aspectos do Cristianismo, o deísmo aproximava-se, cada vez mais, da total negação da religião, característica dos ateus.

Ao deismo succedeu o atheismo, e os atheos empregam contra a Providencia de Deos, na ordem natural, os mesmos argumentos de que os deistas tinham usado contra a Revelação, e contra a mesma Providencia, na ordem sobrenatural. E que outro devia ser o resultado dessa espantosa serie de desvarios, senão o septicismo a incredulidade, o indifferentismo em fim, que igualmente approva todas as religiões, porque nenhuma admitte? Eis aqui as funestissimas consequencias da pretendida reforma! [...]. (GAMA, 1847:4).

Na visão de Tavares da Gama, o deísmo não era uma religião e sim uma opinião. (GAMA, 1847:352). Essa "opinião" era defendida pelos filósofos como uma "religião natural" que norteava-se pela razão para entender a natureza de Deus. Dentro da lógica deísta não poderia haver a Revelação divina. Tavares da Gama foi enfático na crítica ao deísmo: "Não he possível entender-se em que sentido possa chamar-se religião natural huma religião que nunca existio em lugar algum do mundo, e que só deve a sua invenção a philosophos illustrados desde a infancia pela revelação christã." (GAMA, 1847:41).

Em A Voz da Religião, Voltaire é caracterizado como o principal difusor das ideias deístas, isto é, uma corrente de opinião que se mostrava contrária a diversos aspectos do cristianismo, a saber:

Muitas são as especies de deistas. Huns rejeitando, absolutamente toda a Revelação, sustentão que em materia de religião, como em tudo o mais, o homem não deve seguir senão as luzes da sua razão. Outros não duvidão de affirmar que J. Christo foi suscitado por Deos para dar aos homens melhores lições do que as ensinadas pelos sabios que havião precedido. Alguns disserão que não rejeitavão nem admittião positivamente a Revelação [...]. (GAMA, 1847:33).

Não havia, dentro dos defensores dessa "opinião", uma homogeneidade de pensamento. A razão guiava-os na sua relação com Deus e com a natureza, mas como? Essa questão foi tema de um artigo dedicado ao deísmo. (GAMA, 1847:41). O padre questiona: “o que entendem elles por essa imaginada religião natural?" (GAMA, 1847:41). Como a religião natural guia-se unicamente pela razão, sem admitir a Revelação? Os deístas "dizem que" sua religião natural "he o culto que a razão humana, deixada a si mesma, nos ensina que devemos 
dar a Deos." (GAMA, 1847:41). O padre conclui: "Mas a razão humana jamais foi deixada a si mesma, e isto só poderia verificar-se em hum selvagem abandonado desde o seu nascimento, e entregue unicamente à companhia das féras? [...]” (GAMA, 1847:41).

Para esclarecer seus argumentos, o padre reúne alguns preceitos caros aos deístas e pretende demonstrar que o deísmo não passava de "hum systema de irreligião."

Digamos pois que o deismo he a doutrina daquelles que admittem hum Deos sem o definir, hum culto sem o determinar, huma lei natural sem a conhecer, e que rejeitam a revelação sem a examinar. Não he mais do que hum sytema de irreligião mal organisado, ou o privilegio de crer e de fazer tudo o que pede a vontade. [...]. (GAMA, 1847:41).

Como já foi mencionado, Voltaire é um dos representantes da filosofia deísta. Segundo o jornal A Voz da Religião, ele foi o maior representante da "seita irreligiosa deísta". Voltaire foi criticado por ter enganado todos os seus leitores com falácias. (GAMA, 1846:5). Voltaire atacou a Igreja durante toda a sua vida. Segundo um artigo traduzido e publicado no jornal: “A Religião e a Igreja ainda são atacadas de todos os lados por huma multidão de inimigos." (GAMA, 1846:5). Entre esses inimigos estava Voltaire e outros filósofos que "se esforção por seduzir todas as classes." (GAMA, 1846:7). Um artigo publicado pelo Jornal da Sociedade Catholica e reproduzido no número 17 de $A$ Voz da Religião, procurou demonstrar que toda a perniciosidade de Voltaire foi desmascarada no leito de sua morte. Voltaire que "nos dias do seu triunpho, e da sua falsa gloria, os que admirão o seu talento, e a sua fecundia, a sua intrepidez, e as suas blasfemias [...]." (GAMA, 1846:7), agora, no seu leito, viam esse filósofo renegar seus escritos. A verdade estava cobrando seus direitos a Voltaire, que havia enganado e "allienado" muitos homens.

Que terrivel espectaculo! Que importante lição! Ainda há pouco aquela bocca sacrilega vomitava imprecações, e blasfemias contra o Christo do Senhor, e agora, sentindo-se ferido pela sua Omnipotente Dextra, e próximo a submergir-se nessa eternidade tremenda, e assombrosa, agitado pela sua consciência afflitca, e consternada e fluctuando entre desesperação, e a confuança, recorre ao Ceo, invoca o Nome Augusto daquelle, que em suas cartas, em suas obras, e em seus discursos appllidava infame!!! (GAMA, 1846:7).

Esse dia, no qual Voltaire renunciou tudo aquilo que havia defendido, era uma prova cabal da fragilidade do deísmo, sua orientação filosófica.

Vio-se jamais no mundo algum discipulo do Evangelho, que, havendo dirigido a sua conducta pelos seus preceitos e pelas suas maximas, se tenha 
arrependido, nos ultimos momentos de sua existencia, de haver acreditado as verdades que elle ensina, e observado os preceitos que elle impõe? Vio-se algum Christão, que, devorado pelos remorsos, intentasse abjurar a sua crença, quisesse passar da profissão da Fé Catholica à profissão da incredulidade? Nem até aqui se vio, nem jamais se verá similhante fenômeno. (GAMA, 1846:6)

No caminho da "irreligião", o próximo passo, a partir do deísmo, era o ateísmo, que negava a Revelação, como o deísmo, mas, também, a própria existência de Deus. Para Tavares da Gama, o ateísmo "não he essencialmente senão a plenitude do erro.” (GAMA, 1847:1). Segundo seu entendimento, Espinosa, autor do século XVII, havia sido o principal difusor dessa "seita irreligiosa".

Em seus escritos, Espinosa tratou de assuntos polêmicos à época, sobretudo ao propor, a separação entre o Estado e a Igreja. Ele também iniciou debates importantes à filosofia moderna: as reflexões sobre as Sagradas Escrituras como um conjunto de alegorias morais e suas considerações a respeito da substancialidade de Deus, são um exemplo. (GAMA, 1847:1).

Os argumentos de Espinosa iam diametralmente contra as concepções judaico-cristãs, embora ele tenha se formado na tradição judaica ao frequentar a Escola Árvore da Vida e a Academia da Coroa e da Lei. (CHAUÍ, 1997:4). O seu interesse por lógica, medicina e metafísica, consideradas "ciências profanas" despertou a preocupação dos dirigentes da Academia que o convocaram a dar explicações sobre o envolvimento com tais ciências. Espinosa teve de submeter-se a intenso interrogatório, cujo objetivo era demonstrar seu ateísmo. Após esse interrogatório, Espinosa foi excluído da comunidade judaica e, mesmo que o seu "ateísmo" não tenha sido provado, foi sob esse rótulo que Baruch de Espinosa ficou conhecido em boa parte da literatura dedicada à sua obra.

Suas formulações a respeito de Deus também contribuíram para a atribuição do qualificativo de ateu a Espinosa. Contudo, ele jamais refutou a existência de um Deus. Em sua opinião, "Deus" não poderia ser reduzido à explicações e formulações que tentassem restringir a concepção desse Ente.

Há quem imagine que Deus, à semelhança do homem, é composto de corpo e de alma, sujeito a paixões, mas das demonstrações precedentes resulta quanto tais pessoas estão longe do conhecimento de Deus. Deixo-as, porém, de lado, pois todos os que têm considerado, por pouco que seja a natureza divina, negam que Deus seja corpóreo; o que provam muitíssimo bem [...]. (ESPINOSA, 1997:166-167).

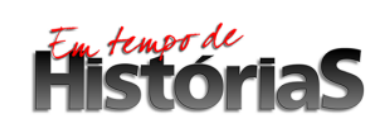


Espinosa conclui sobre a substância divina: “[...] fora de Deus não pode haver nem ser concebida nenhuma substância, donde concluímos que a substância é um dos atributos infinitos de Deus.” (ESPINOSA, 1997:166-167) Marilena Chauí ajuda-nos a compreender essa questão central no pensamento de Espinosa.

[...] Espinosa afirma que Deus é matéria e não um puro espírito como sempre foi afirmado pela filosofia. [...] Amplia até o ponto extremo a ideia de total homogeneidade entre Deus e a Natureza e, portanto, das leis divinas e naturais. Por outro lado, ao afirmar que o pensamento é um atributo de Deus, afirma a total inteligibilidade do real, não podendo haver nada que deixe de ser compreensível. Entre outras coisas, essa afirmação destrói definitivamente a noção do milagre e da vontade divina. (CHAUÍ, 1997:15).

Espinosa entendia que Deus e a natureza eram uma só substância, inseparável. Tavares da Gama, para combater essa afirmação, traduziu e publicou um texto do jornal francês l'Ami de la Religion.

\begin{abstract}
Accusados de confundir Deos com a natureza, tem protestado contra esta accusação, mas não tem podido demonstrar que ella seja falsa. Para separar as suas doutrinas do pantheismo, huns, depois de terem estabelecdo os principios desse erro monstruoso, negão arbitrariamente as consequencias; outros preconisando alternativamente Spinosae, Hégel, Descartes e Leibnitz, tem seguido direcções as mais contrarias, persistindo sempre em sustentar que são Christãos e Catholicos. (GAMA,1847:292).
\end{abstract}

Tavares da Gama, ao escrever a respeito da corrente filosófica denominada racionalista, da qual, segundo seu entendimento, Espinosa era o maior representante, conclui que Espinosa era, na realidade, um ateu. (GAMA,1847:292).

Spinosa pode ser considerado como o primeiro fundador da eschola racionalista. Nos seus escriptos, especilamente nas suas cartas, encontra-se o germen das doutrinas anti-christãs e impias que acabamos de indicar. He verdade que o principio do livre exame e a negação de toda a authoridade em materia de fé [...]. (GAMA, 1848:154).

A superstição, para Espinosa, era um artifício que os homens, através da imaginação, criavam para entender as questões do Universo. A imaginação fomentava, segundo Espinosa, a imagem de um "ser supremo e todo-poderoso, que existiria fora do mundo e o controlaria segundo seu capricho”. (CHAUÍ, 1997:10). Essa projeção em um ser supremo e em um Deus com características humanas levaria o homem a compreender, de forma não racional, a existência dessa substância - Deus -. O medo perante o desconhecido seria "a causa que 
origina, conserva e alimenta a superstição.” (ESPINOSA, 2003:6).

Segundo Tavares da Gama, a qualificação das tradições cristãs de culto, adoração e leitura da Bíblia como superstições por parte de Espinosa, era simplesmente absurda.

Sem fundamento se diz que para distinguir o que he ou não he superstição, deve consultar-se a razão. Se consultarmos a razão dos incredulos, a maior parte nos dirão que todo o culto he supersticioso, e quando não affirme que não há Deos, dirão pelo menos que elle não exige de nós culto algum. Os fundadores das differentes seitas [...] seguiram, sem duvida, as luzes da sua razão. (GAMA, 1848:267).

Espinosa, e boa parte dos filósofos considerados racionalistas, tinham uma visão da bíblia como "alegorias morais". A respeito dessa assertiva o padre Tavares da Gama alertava:

[...] huma eschola de pretendidos doutores ou theologos, que à força de quererem fazer concordar as Santas Escrituras com eles apellidão - a Sciencia da nossa epocha - acabaram reduzindo-as a não conterem senão huma serie d'allegorias e de mythos (fabulas) desprovidas de todo o valor historico e sobrenatural. (GAMA, 1847:153).

O entendimento de Espinosa a respeito das Sagradas Escrituas era categórico. Em carta enviada à Wilhelm Blyenbergh, ele suscitou algumas questões que seriam aprofundadas posteriormente em seu livro Tratado Teológico-Político.

\begin{abstract}
Afirmo que, embora não atribua às Escrituras o tipo de verdade que pareceis querer encontrar nelas, contudo, creio que reconheci sua autoridade tanto ou até mais do que os outros e fui muito cauteloso do que outros que se acautelam para não introduzir nelas opiniões pueris ou absurdas que ninguém pode fornecer, a menos que tenha compreendido extremamente bem a filosofia ou que tenha tido revelações divinas. Por isso não me pertubo muito com as explicações que certos teólogos vulgares dão das Escrituras, sobretudo se são daquela laia que se consagra à mera letra e ao sentido exterior. Nunca encontrei entre os teólogos, [...], algum tão crasso que não compreendesse que as Escrituras falam de Deus dum modo humano e que exprimem seu sentido por meio de parábolas. (ESPINOSA, 1997:542).
\end{abstract}

Para Tavares da Gama, essa compreensão das Sagradas Escrituras era infundada, pois não se compreendia as Escrituras pela razão e sim pela fé e pela Revelação. Os filósofos racionalistas empenharam-se em relacionar as Sagradas Escrituras às leis naturais do universo, "a fim de extrahirem dos livros Santos - huma doutrina moral e racional conforme á sciencia." (GAMA, 1847:2). O padre conclui que:

De Espinosa pois he que nasceu a interpretação da Biblia pelos phenomenos

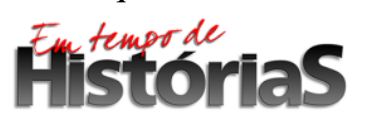

(PPGHIS/UnB) №. 26, Brasília, Jan- Jul 2015 ISSN 2316-1191 
naturaes: porque elle affirmava que tudo o que se contem nos livros revelados, se tinha passado de hum modo conforme ás leis estabelecidade no universo. Assim, por exemplo, pelo que pertence aos Evangelhos, elle não admittia, segundo a lettra. (GAMA, 1847:2)

A razão humana, segundo Tavares da Gama, é incapaz de compreender a realidade divina. O padre, com o objetivo de combater a primazia da razão, publicou o artigo A Religião Christã he a principal Obra da Sabedoria de Deos, assinado pelo padre Duro, no qual discute a inútil tentativa do uso da razão para compreender as questões divinas.

Seria isto querer que o finito podesse comprehender o infinito; cousa que ainda os mais habeis Philosophos não tem emprehendido, por temerem ficar, como diz S.Paulo, confundidos em suas mesmas idéas. Para darmos disto algumas provas, observemos os planos mais famosos que o homem tem formado nesta materia, e não encontraremos nellas mais que delirios da razão. (GAMA, 1846:4).

Apesar de suas críticas, o padre Tavares da Gama não rejeitava a importância da razão. Da Gama entendia que a razão era importante para compreender alguns aspectos sobre o mundo e sobre as ciências. Entretanto, o padre preocupava-se com a defesa da predominância da razão em detrimento da fé. Em sua opinião, deveria haver um equilíbrio entre a razão e a fé, e quando o homem estivesse em dúvida, deveria recorrer sempre à fé e às Sagradas Escrituras. (GAMA, 1846:3).

O homem moderno consta em um artigo, com todo o seu conhecimento sobre os astros e sobre os metais, não pode "só com o socorro das luzes da razão [...] chegar ao seio da Divindade".

Usa da razão o atheista, quando não quer por hum lado reconhecer hum Deos que existe eternamente, dando por outro lado huma origem eterna a tudo o que existe no mundo? Usa rectamente da razão o deista, quando por huma parte admitte hum Deos, isto he, hum ser infinitamente sabio, e por outro nol-o representa como hum Deos insensivel à sua própria gloria, surdo ás nossas supplicas, indifferente em nossas necessidades, e cego ás nossas acções? Usa exactamente da razão o espinosista, quando pretende que não há no mundo mais que huma só e única substancia; e não he absurdo dizer que nossa alma he substancialmente huma mesma cousa com a materia? [...]. (GAMA, 1846:3).

A defesa da harmonia entre a razão e a fé é uma característica era uma constante nos textos dos autores ligados à Apologética Cristã. 


\section{Conclusão}

O jornal A Voz da Religião revelou-se uma fonte riquíssima e, embora tenha permanecido desconhecida dos historiadores, mostrou-se profícua ao revelar detalhes sobre a circulação de textos e ideias em Pernambuco ao longo do século XIX. A redação e a seleção de artigos que compõem o periódico também revelam o perfil intelectual de um eclesiástico esclarecido do Brasil oitocentista. O padre Tavares da Gama teve contato com diversos assuntos que agitavam a intelectualidade europeia e seu jornal, em alguma medida, cumpriu a função de divulgar essas ideias no Império do Brasil.

O padre apresentou muitos filósofos em seu jornal: Espinosa, Voltaire, Rousseau, Montesquieu, John Locke, Isaac Newton, David Hume, Shaftesbury, Edmund Burke, Kant, Hegel, Leibnitz, Madame de Staël, Schelling, Diderot e d'Alembert são apenas alguns deles que são mencionados nas páginas do seu periódico. Muitos desses filósofos foram apresentados como blasfemadores e representantes de uma literatura irreligiosa.

Os filósofos da Apologética Cristã mereceram destaque nas páginas do periódico, Joseph de Maistre, Louis de Bonald, Bollanche, Bergier e Chateubriand, por exemplo, compuseram a ala da filosofia católica, a qual o padre buscou defender nos artigos de seu jornal.

Cabe ressaltar que Tavares da Gama não rejeitou totalmente as idéias veiculadas pelos filósofos. O periódico pode ser considerado um exemplo de "uma peculiar articulação das novas ideias à antiga tradição". (KIRSCHNER, 2009:300). Esse cruzamento entre a filosofia moderna e a tradição católica fez-se presente no discurso de muitos ilustrados católicos, quando "eruditos católicos entretinham [...] um frutífero diálogo com a filosofia herdada de Newton e de Locke, participando do clima, opinião e dos debates de seu tempo. Rejeitando o ateísmo, conciliaram os valores cristãos e as conquistas da filosofia moderna." (KIRSCHNER, 2009:300). O jornal A Voz da Religião, de alguma maneira, é representativo desse cruzamento.

Por isso, é difícil definir categoricamente o jornal A Voz da Religião. Pensar em termos de dicotomias rígidas acaba simplificando muito a complexidade característica do mundo das ideias. Seguindo a lógica do historiador americano Jonathan Israel, o periódico em questão poderia ser considerado como um representante do que, em suas palavras, seria o Iluminismo Moderado, ou seja, o Iluminismo que acabou predominando, reunindo autores que 
conciliaram a razão com a fé e com a tradição e se opuseram aos filósofos considerados radicais - aqueles que defendiam a primazia da razão. (ISRAEL, 2001). Em alguma medida, o jornal A Voz da Religião enquadra-se nessa definição de Israel.

A antifilosofia é muito complexa e ela teve um papel ativo na crítica ao Iluminismo. Ao estudá-la percebemos não só a maneira como os textos filosóficos foram recebidos à época de suas publicações, mas também como foram apropriados em diferentes recortes temporais e geográficos.

Trabalhar com o pensamento de Espinosa e Voltaire revelou-se um desafio, e o objetivo foi tentar captar as apropriações realizadas pelo jornal oitocentista.

A interpretação de Tavares da Gama sobre a filosofia de Espinosa e Voltaire é categórica. A razão deve estar subordinada à fé e à Revelação. Contrariar esse princípio significa cair no erro. O padre aceitava as ideias modernas desde que não se opusessem aos valores cristãos. Trata-se de "[...] preservar e proteger o que eram considerados elementos essenciais das antigas estruturas, efetuando uma síntese viável entre o velho e o novo, e entre a razão e a fé.” (ISRAEL, 2001:11).

\section{Referências Bibliográficas}

Fontes:

\section{Periódicos}

GAMA, Francisco José Tavares da. A Voz da Religião, Typographia: Recife, 1846-1848.

ALMEIDA, Raposo de. Elogio Historico do conego da capella imperial Francisco José Tavares da Gama lido em sessão especial do instituto historico de Goianna. In: Revista do Instituto Histórico de Goianna. Tomo Primeiro. Goianna: Typographia Comercial. 1871.

\section{Livros}

ESPINOSA, Baruch de. Os pensadores. São Paulo: Nova Cultural, 1997.

Tratatado teológico-político. São Paulo: Martins Fontes, 2003.

VOLTAIRE, Dicionário Filosófico. São Paulo: Nova Cultural, 1988.

\section{Bibliografia:}

BERLIN, Isaiah. The Counter-Enlightenment. In: BERLIN, Isaiah. Against the Current. Essays in the history of ideas. New Jersey: Princeton University Press, 2001.

CHAUÍ, Marilena de Souza. Espinosa, vida e obra. In: ESPINOSA, Baruch. Espinosa, os pensadores. São Paulo: Nova Cultural, 1997.

1988.

Voltaire, vida e obra. In: VOLTAIRE, Dicionário Filosófico. São Paulo: Nova Cultural,

ESPINOSA, Baruch de. Os pensadores. São Paulo: Nova Cultural, 1997. 
Tratado teológico-político. São Paulo: Martins Fontes, 2003.

GARRANDER, Graeme. Rousseau's counter-Enlightenment. A republican critique of the philosophes. New York: State University of New York Press, 2003.

GAULTIER, L'abbé Jean-Baptiste. Les Lettres persanes convaincues d'impiété, 1751. In: GUYAUX, André. Mémoire de la critique. Paris: Presses de l'Université de Paris-Sorbonne, 2003.

ISRAEL, Jonathan I. Radical Enlightenment, philosophy and the making of modernity 1650-1750. Oxford: Oxford University Press, 2001.

. Enlightenment Contested: philosophy, modernity, and the emancipation of a man: 16701752. Oxford: Oxford University Press, 2008.

- Democratic Enlightenment, Philosophy, Revolution, and Human Rights 1750-1790. Oxford: Oxford University Press, 2011.

KIRSCHNER, Tereza Cristina. José da Silva Lisboa, Visconde de Cairu. Itinerários de um ilustrado lusobrasileiro. São Paulo: Alameda, Belo Horizonte, MG: PUC-Minas, 2009.

KURY, Lorelai (org). Iluminismo e império no Brasil: O Patriota (1813-1814). Rio de Janeiro: Editora Fiocruz, 2007.

MASSEAU, Didier. Les ennemies des philosophes. L'antiphilosophie au temps des Lumières. Paris: Éditions Albin Michel S.A, 2000.

McMAHON, Darrin M. Enemies of the Enlightenment. The French Counter-Enlightenment and the making of modernity. Oxford: Oxford University Press, 2001.

PALMER, Robert. Catholics and Unbelievers in Eighteenth-Century France. Princeton: Princeton University Press, 1939.

SALDANHA, Jozé da Natividade. Poemas oferecidos aos Amantes do Brazil por seu autor Jozé da Natividade Saldanha, natural de Pernambuco, e estudante do terceiro ano de leis na Universidade de Coimbra. Coimbra: 1822.

STERNHELL, Zeev. The anti-enlightenment tradition; tradução de David Maisel. Yale University: 2010. 